09

\title{
Формирование микротурбин методом прямой лазерной записи по фоторезисту
}

\author{
(C) Р.В. Скиданов, ${ }^{1,2}$ О.Ю. Моисеев, ${ }^{1,2}$ С.В. Ганчевская ${ }^{1,2}$ \\ ${ }^{1}$ Институт систем обработки изображений РАН, \\ 443001 Самара, Россия, \\ ${ }^{2}$ Самарский государственный аэрокосмический университет им. акад. С.П. Королева \\ (Национальный исследовательский университет), \\ 443086 Самара, Россия \\ e-mail: sofi@smr.ru
}

(Поступило в Редакцию 9 марта 2016 г.)

Описан метод формирования микромеханических элементов для приема вращательного момента (микротурбин) от вихревых световых пучков. Приведены результаты экспериментального изготовления большого количества микротурбин. Приводятся результаты измерения формы микротурбин на оптическом микроскопе, интерферометре белого света ZYGO и электронном микроскопе.

DOI: 10.21883/JTF.2018.06.46021.1795

\section{Введение}

В тематике оптической микроманипуляции одной из главных тем является использование вихревых световых пучков для осуществления оптического привода микромеханических систем [1]. Для передачи вращательного момента светового пучка в микромеханическую систему необходимо сформировать микрообъект специальной формы (микротурбину), при этом форма микрообъекта должна обеспечивать максимальную эффективность передачи вращательного момента в вихревом световом пучке. Этого можно достичь точным воспроизведением формы поверхности микротурбины в процессе изготовления. Так как трехмерные микро- и наноструктуры, выполненные из разнообразных материалов произвольной формы или имеющие сложную архитектуру, в последнее время используются в различных областях науки: фотонике, оптоэлектронике, медицине и др., технология их изготовления в значительной степени отработана. Для изготовления трехмерных объектов используют такие технологии, как двухфотонная полимеризация, многолучевая голография, анизотропное травление, а для тиражирования - 3D-наноимпринтинг. Наиболее удобным и точным методом является технология двухфотонной полимеризации [2-8].

В работе [2] создан привод с винтами Архимеда с несколькими лопастями. Радиус винта составил $2 \mu \mathrm{m}$ при высоте $5 \mu \mathrm{m}$, разрешение $0.12 \mu \mathrm{m}$. При этом погрешность воспроизведения формы изготовленного винта в работе [2] не определялась. В [3] уже продемонстрирована оптически управляемая микромеханическая система с винтом Архимеда в качестве механического привода в виде центральной сферы и трех рабочих лопастей микромиксера, которые также были изготовлены методом двухфотонной полимеризации. Лазерный пучок фокусируется на микросистеме, микровинт попадает в ловушку в точке фокусировки и одновременно враща- ется. В работе [3] исследовано как меняется отношение частоты вращения микророторов к мощности вращающего пучка с рабочими лопастями и без них. Рассчитаны и приведены значения, равные $1.9 \mathrm{~min} \cdot \mathrm{mW}^{-1}$ для вращения с рабочими лопастями и $13.5 \mathrm{~min} \cdot \mathrm{mW}^{-1}$ без них. В работе [4] исследованы отношения частоты вращения микророторов к мощности вращаемого пучка от толщины лопасти и центральной части винта. Однако надо заметить, что основной механизм увеличения частоты вращения микрообъектов - увеличение мощности светового пучка, а двухфотонная полимеризация позволяет создавать трехмерные структуры на основе полимеров, которые не обладают достаточной лучевой стойкостью. Для преодоления этой проблемы в [5] разработаны металлизированные, крестообразные роторы (диаметр $40 \mu \mathrm{m}$ ) для микроприводов путем сканирования лазерного луча с низким энергопотреблением. Металлизированные микророторы были изготовлены с помощью комбинации двухфотонных микротехнологий: химической металлизации и лазерной абляции. Проведен анализ светового давления, оказываемого на лопасть, показано, что наклонная лопасть может генерировать больший вращающий момент, чем горизонтальная лопасть, за счет отражения падающего Гауссового пучка. В работе [6] также разработана металлизированная микротурбина (диаметр $60 \mu \mathrm{m}$, высота $6 \mu \mathrm{m}$ ), которая эффективно использовалась для создания движения потоков жидкости. Также на основе технологии двухфотонной полимеризации предпринимались усилия по миниатюризации дифракционного оптического элемента (ДОЭ) для формирования вихревых световых пучков [7]. В результате ДОЭ для формирования вихревого пучка по масштабу был сопоставим с вращаемыми микрообъектами (диаметр $9 \mu \mathrm{m}$, при разрешении $0.3 \mu \mathrm{m}$ ). В [8] уже разработана довольно сложная конструкция оптического привода микронасоса на основе двойного спирального микроротора. 
К сожалению, двухфотонная полимеризация имеет и ярко выраженный недостаток - значительные временные затраты при изготовлении трехмерных структур, и, как следствие, микротурбины по этой технологии изготавливаются поштучно. Однако для изготовления подобных компонент для микромеханических структур уже довольно давно используется технология фотолитографии. Так, в конце прошлого века значительно увеличился спрос на компактные источники питания для портативной электроники. Для них методом фотолитографии изготавливались турбины миллиметрового размера. Такие устройства известны как микроэлектромеханические системы (МЭМС). Компоненты МЭМС (микротурбины) изготавливались, например, с помощью фотолитографии и ионного травления на отдельных кремниевых пластинах [9]. Применение МЭМС технологии позволяет получать микромеханические и оптические узлы значительно меньших размеров, чем это возможно с помощью традиционных технологий. Так, в работе [9] для создания трехмерных микромеханических элементов используют ионное травление, при этом достигается погрешность изготовления отдельных элементов $0.56 \mu \mathrm{m}$. В то же время технология позволяет получать довольно прочные элементы. Так, в работе [10] рассматриваются микророторы для работы на линейных скоростях края турбины до $300 \mathrm{~m} / \mathrm{s}$. Кремниевые высокоскоростные механизмы вращения используются для питания микроэлектромеханических систем, таких как портативные преобразователи энергии, насосы и компрессоры [11], датчики скорости и расхода массы [12].

На основе технологии фотолитографии можно изготавливать и микротурбины с размерами, подходящими для оптического привода. Более того, самые первые работы по вращению микротурбин изготовлены методом фотолитографии [13]. В последнее время появились работы по скоростному вращению микротурбин с формой поверхности, оптимизированной под форму вихревого светового пучка [14]. Однако, как следует из вышеприведенного обзора, во всех работах по изготовлению микротурбин не анализируется ни погрешность изготовления, ни то, как эта погрешность может влиять на свойства микротурбины.

В настоящей работе рассматривается метод изготовления микротурбин на основе засветки ультрафиолетовым пучком толстослойного фоторезиста. Данный метод выгодно отличается от технологии двухфотонной полимеризации скоростью формирования микротурбин и точностью.

\section{1. Прямая лазерная запись квазиполутонового (гладкого) микрорельефа}

Запись полутоновых микроструктур производилась на станции круговой лазерной записи CLWS-2014, работающей в полярной системе координат. На рис. 1 представ- лена схема записи небольшого участка полутонового рельефа.

Отличительной особенностью станции является двухступенчатая система автофокусировки, с помощью которой можно осуществлять запись не только на плоских, но и на сферических поверхностях. В основе процесса лазерной записи лежит фотодеструкция фоторезистов на основе диазасоединений сфокусированным лучом лазера с длиной волны $405 \mathrm{~nm}$.

Для изготовления микротурбин на поверхность кварцевой подложки наносился слой фоторезиста AZ4562 толщиной около $8 \mu \mathrm{m}$, обработанный стандартным способом. Профиль полутонового рельефа микротурбин формировался путем последовательной засветки актиничного лазера с изменяемой мощностью в зависимости от радиуса. В работе [15] для получения линейной характеристики фоторезист предварительно засвечивается ультрафиолетом на установках совмещения и экспонирования. При изготовлении микротурбин для уменьшения влияния нелинейности контрастной характеристики фоторезиста начальная точка кривой изменения мощности засвечивающего лазера подбиралась таким образом, чтобы использовать именно линейный участок.

\section{2. Формирование агломерации микротурбин на поверхности подложки}

Перед записью микротурбин на слое фоторезиста был сформирован фотошаблон, в котором использовались полутоновые изображения структуры микротурбин.

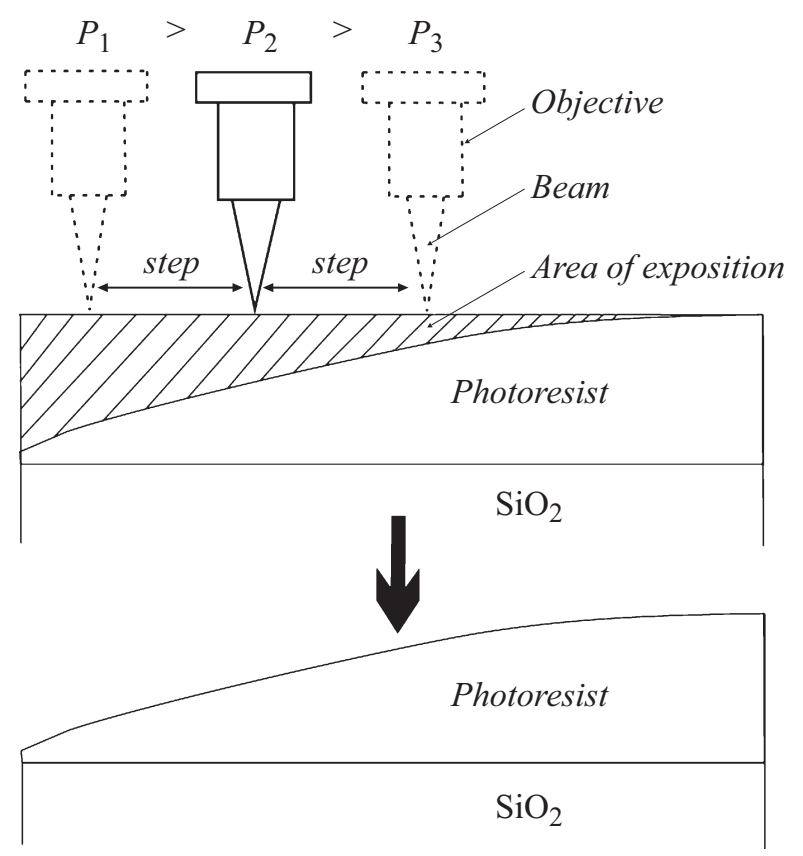

Рис. 1. Схема получения участка полутонового рельефа. $P_{1}, P_{2}, P_{3}-$ мощности пучка, соответствующие положению фокусировки. 


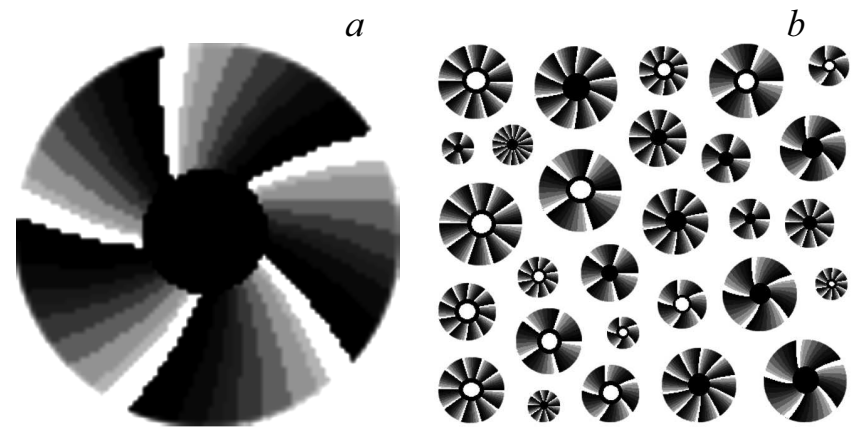

$c$

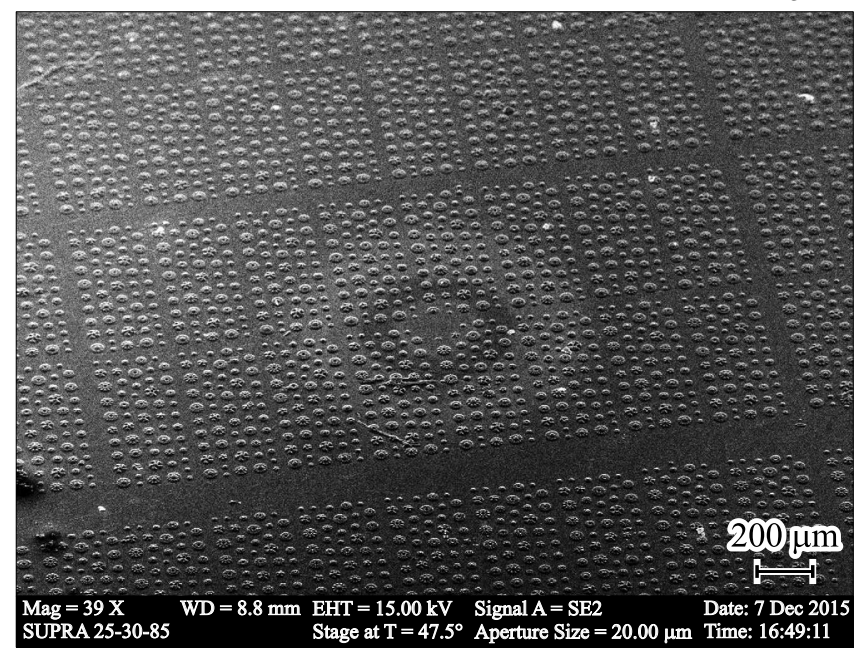

Рис. 2. Изображения формы микрорельефа отдельной микротурбины $(a)$ и базового участка агломерации микротурбин (b) в виде полутонового файла (256 градаций серого), вид центральной части агломерации микротурбин, полученный на электронном растровом микроскопе Supra $(c)$.

Пример такого изображения приведен на рис. 2,a. Черный цвет соответствует максимальной высоте поверхности микротурбины, белый - нулевой высоте. Для формирования фотошаблона всего было использовано 27 типов микротурбин диаметром 50-100 $\mu \mathrm{m}$ и с разным количество лопастей (5-10). Все изображения структуры микротурбин объединены в базовые группы рис. $1, b$, которые затем были многократно скопированы по изображению размерностью $12000 \times 12000$ пикселей. Общее количество микротурбин, таким образом, более 10000 . Сформированное изображение было использовано в качестве шаблона в процедуре прямой лазерной записи по фоторезисту, описанной в разд. 1. На рис. 1, $c$ представлено изображение центральной части микрорельефа с микротурбинами, полученного на электронном растровом микроскопе Supra. Для получения четкого изображения на микротурбины и поверхность подложки был нанесен тонкий слой хрома $(20 \mathrm{~nm})$, который в последующем удалялся перед отделением микротурбин от подложки, а при измерении не оказывал существенного влияния на результаты.
Сформированные микротурбины были измерены несколькими способами: на оптическом микроскопе, на электронном микроскопе, на интерферометре белого света. На рис. 3, а представлено изображение одиночной пятилопастной микротурбины с расчетным диаметром $100 \mu \mathrm{m}$, по результатам измерения реальный диаметр микротурбины составил $100 \pm 1 \mu \mathrm{m}$. На рис. $3, b$ представлен базовый участок агломерации размером $1400 \times 1500 \mu \mathrm{m}$, содержащий все типы микротурбин.

Из рис. 3, $b$ можно сделать два вывода: реальные размеры сформированных микротурбин совпадают с расчетными, форма полученных микротурбин качественно совпадает с расчетной формой.

Для более точного измерения формы были использованы приборы, позволяющие определить высоту поверхности микротурбин. На рис. 4, а такое измерение было проведено для одной из лопаток пятилопастной
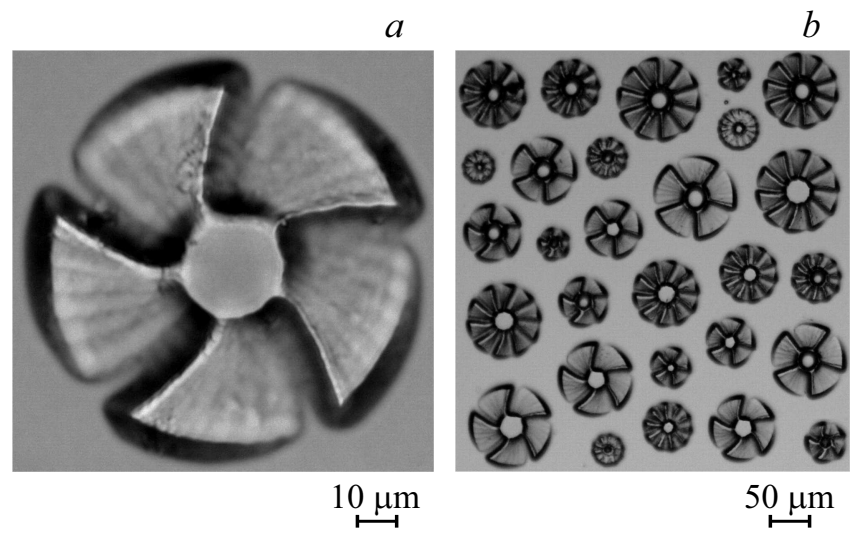

Рис. 3. Внешний вид одиночной микротурбины диаметром $100 \mu \mathrm{m}(a)$ и базового участка агломерации микротурбин $(b)$, полученный на оптическом микроскопе.

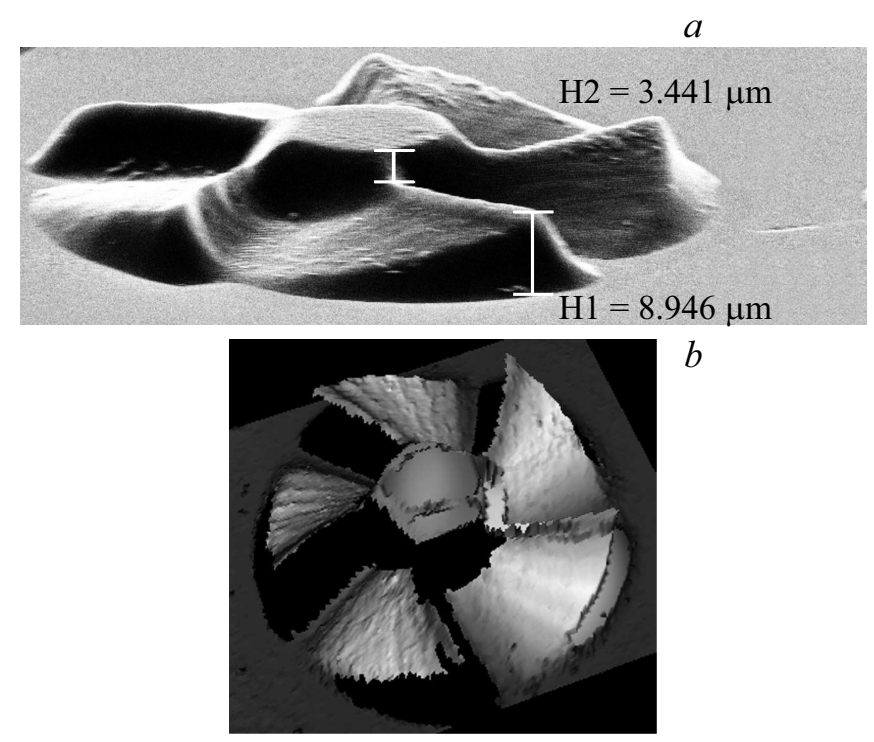

Рис. 4. Форма поверхности микротурбины, полученная на растровом электронном микроскопе Supra $(a)$, на интерферометре белого света New View Zygo $5000(b)$. 
микротубины диаметром $100 \mu \mathrm{m}$ (рис. $3, a$ ). В результате измерения получена высота лопатки микротурбины около $8.9 \mu \mathrm{m}$. Для получения полной формы поверхности микротубины был использован интерферометр белого света New View Zygo 5000. На рис. 4, $b$ представлена реконструкция формы пятилопастной микротурбины. По результатам измерения высота лопаток микротурбины составляет около $8.6 \mu \mathrm{m}$.

Таким образом, высота микротурбин составляет $8.6-8.9 \mu \mathrm{m}$, что очень хорошо согласуется с толщиной слоя фоторезиста $(9 \mu \mathrm{m})$.

\section{Заключение}

Представленная технология изготовления микромеханических элементов позволяет достичь погрешности формирования поверхности $0.1 \mu \mathrm{m}$ при размере минимального элемента $1 \mu \mathrm{m}$. При этом технология обеспечивает возможность тиражирования элементов, что позволяет за счет выбора элемента обеспечить высокое качество рабочих микромеханических структур. Таким образом, можно говорить о преимуществе представленной в настоящей работе технологии перед традиционными технологиями изготовления элементов микромеханики, такими как двухфотонная полимеризация и фотолитография.

\section{Благодарности}

Работа выполнена при финансовой поддержке Министерства образования РФ в рамках выполнения государственного задания 3.3025.2017/4.6.

\section{Список литературы}

[1] Higurashi E., Ukita H., Tanaka H., Ohguchi O. // Appl. Phys. Lett. 1994. Vol. 64. P. 2209-2210.

[2] Baldeck P., Lina Ch.-L., Lina Yu-Sh., Linb Ch.-Te, Chungb T.T., Bouriauc M., Vitrantd G. // Proc. SPIE. 2011. Vol. 8097. P. 809713 .

[3] Liu Yi-J., Lee Yi-H., Lin Yu-Sh., Tsou Ch., Baldeck P.L., Lin Ch.-L. // Actuators. 2013. Vol. 2. N 2. P. 19-26.

[4] Lina Ch.-L., Lina Yu-Sh, Baldeck P. // Micromachines. 2015. Vol. 6. P. 674-683.

[5] Ikegamil T., Ozawal R., Stocker M.P., Fourkas J.T., Maruo S. // JLMN-Journal of Laser Micro/Nanoengineering. 2013. Vol. 8. N 1. P. 6-10.

[6] Ikegamil T., Ozawal R., Stocker M.P., Fourkas J.T, Maruo S. // 16th Intern. Conf. on Miniaturized Systems for Chemistry and Life Sciences. 2012. Vol. 5. P. 139.

[7] Knoener G., Parkin S., Nieminen T.A., Loke V.L.Y,, Heckenberg N.R., Rubinsztein-Dunlop H. // Opt. Expres. 2007. Vol. 15. N 9. P. 5521-5530.

[8] Maruo S., Takaura A., Saito Y. // Opt. Express. 2009. Vol. 17. N 21. P. $18525-32$

[9] Waits C.M., Morgan B., Kastantin M., Ghodssi R. // Sensors and Actuators A: Phys. 2005. Vol. 119. N 1. P. 245-253.
[10] Frechette L.G., Jacobson S.A., Breuer K.S., Ehrich F.F., Ghodssi R., Khanna R., Chee Wei Wong, Zhang Xin, Schmidt M.A., Epstein A.H. // J. Microelectromechanical Systems. 2005. Vol. 14. N 1. P. 141-152.

[11] Fréchette L.G., Jacobson S.A., Breuer1 K.S., Ehrich F.F., Ghodssi R., Khanna R., Chee Wei Wong, Xin Zhang, Schmidt M.A., Epstein A.H. // Sol.-Stat. Sensor and Actuator Workshop (TRF Cat. No.00TRF-0001). 2000. P. 43-47.

[12] Werner Brenner, Franz Suemecz, Aleksandar Vujanic. // Proc. IEEE. 2002. Vol. 2. P. 1757-1761.

[13] Friese M.E.J., Rubinsztein-Dunlop H., Gold J., Hagberg P., Hanstorp D. // Appl. Phys. Lett. Vol. 78. N 4. P. 547-549.

[14] Xiao-Feng Lin, Guo-Qing Hu, Qi-Dai Chen, Li-Gang Niu, Qi-Song Li, Ostendorf A., Hong-Bo. // Appl. Phys. Lett. 2012. Vol. 101. P. 113901.

[15] Zhizhchenko A.Y., Vitrik O.B., Kulchin Y.N., Mirochnik A.G., Fedorenko E.V., Lv G., Shalagin A.M., Korolkov V.P. // Opt. Communicat. 2013. Vol. 311. P. 364-367. 